\title{
Pobreza en Colima. Familias, estrategias e historias de vida ${ }^{1}$
}

\author{
Salvador Alejandro Ochoa López*
}

\section{Introducción}

Si se mirase como un trabajo académico, exclusivamente de investigación social y crítico en su fondo o forma, sin duda habremos encontrado un estudio meramente intelectual que trasciende no solo de ser un libro digno de consultar en innumerables ocasiones, sino a una obra literaria para examinarse desde los rubros económicos, antropológicos, demográficos, educativos y psicosociales. Por otro lado, si el lector lo toma como un texto de carácter emocional, con trasfondo profundo, hallará un cúmulo de historias conmovedoras, capaces de calar las fibras más sensibles del ser y producir en varios momentos nudos en la garganta que aprietan muy fuerte, dando como resultado una toma de conciencia sobre el problema que aborda. Una consecuencia de su lectura es que nos lleva a valorar nuestra propia vida, la ropa que vestimos, las cosas que tenemos o el plato de comida servido en la mesa; ese confort (concepto precisado en esta magnífica literatura) cotidiano, que la sociedad lo etiqueta como calidad de vida.

La doctora Virginia Romero Plana agradece a Colima por tantos "apapachos recibidos", amistades y oportunidades brindadas. Es necesario precisar, somos nosotros quienes como colimenses debemos agradecerle por mostrarnos la audacia, el emprendimiento por encontrar vías para superarse, esa generosidad tan característica en ella, que nos comparte sus conocimientos sobre un tema importante de la identidad cultural del estado. La autora es de nacionalidad española, pero no es malinchismo lo circunscrito, más bien

\footnotetext{
${ }^{1}$ Romero Plana, V. (2016). Pobreza en Colima. Familias, estrategias e historias de vida. Colima: Archivo Histórico del Municipio de Colima y Secretaría de Cultura del Gobierno del Estado de Colima.

${ }^{+}$Estudiante de posgrado. Estancia en la Universidad de Colima, crossedu69@gmail.com
}

podríamos nosotros como nativos contribuir de la misma manera en escribir investigaciones sobre nuestro propio entorno. La escritora señala que su estadía fue un "proceso duro y bonito en el que me caí y levanté muchas veces". Este carácter y voluntad de superación se refleja en la impecable redacción e interpretación de las historias de vida de las familias mostradas.

\section{Revisión de los capítulos}

En el capítulo 1: "La pobreza en Colima. Un acercamiento a la realidad", se analizan con precisión datos estadísticos sobre, en primer sitio, la cantidad poblacional colimense, cuya cifra es de 650555 habitantes, de acuerdo con el Instituto Nacional de Estadística y Geografía (INEGI) en el año 2010. Además, clarifica sobre la duplicación de los hogares con jefatura femenina en los últimos años. La doctora Romero ha interpretado con exactitud que a pesar de no tener índices altos de pobreza en comparación con otros estados, en Colima se dio un aumento en este índice del 27. 4 al $34.7 \%$ del año 2008 a 2010, lo cual nos alerta que no hay que dejar de luchar contra este fenómeno y que debemos de comenzar a crear soluciones o alternativas para disminuir o erradicar dicho fenómeno social.

La selección de familias para realizar la investigación se basó en los datos proporcionados por el AGEB (Áreas Geo-estadísticas Básicas), triangulados con la información brindada por el INEGI. El libro expone las historias de vida de cinco familias, las cuales viven en las colonias El Tívoli, Insurgentes, La Albarrada y también en la San Rafael. En una reveladora tabla, cuya elaboración fue de la autora, nos muestra el nivel de marginación de las familias, las colonias donde viven y los apellidos de las mismas. Los nombres de las personas que integran a estos núcleos familiares no son los reales, ya que por ética profesional se sustituyeron para mantener confidencialidad. 
En el capítulo 2: "Estudios de caso: cinco familias", la autora focaliza la investigación en detectar las colonias con más pobreza en Colima y sintetiza en el marco metodológico los criterios para seleccionar a las familias (accesibilidad para entrevistarlas y el número de miembros y estabilidad de ingresos).

Describe la contextualización de las familias, que es el núcleo de la obra, con una redacción impecable que permite una lectura fluida y una comprensión plena del tema. Así nos enteramos, por ejemplo, que en la familia Martínez hay seis hijos, todos son mayores de edad y que la jefa de familia, de nombre Myrna, es viuda. La autora incluye una pequeña reseña de la vida de cada miembro de la familia, para que en su conjunto percibamos a detalle la complejidad de las relaciones que se dan en ese hogar. Al igual que este núcleo familiar, se narran cuatro casos más, todos con dosis de dolor que nos conmueven, indignan, entristecen y causan rabia ante la desigualdad del capitalismo.

El capítulo 3: "Relaciones y estrategias familiares", es sumamente interesante. En él se abordan elementos básicos para comprender la pobreza en el estado y se subraya la interacción existente en el hogar. Este prístino estudio social describe a la familia tanto en su conformación como en las estrategias empleadas para salir adelante, "Como unidad básica social, por su estructura, su permanencia, sus relaciones intra y extra sociales del propio hogar, su participación en grupos más amplios y por sus valores transmitidos endoculturalmente" (Romero, 2016:47).

Colima mantiene una caracterización única dentro de las relaciones sociales, se destaca la fraternidad comunal entre grupos y la convivencia familiar que existe dentro de casa, a esto se agregan las estrategias para la solvencia y salvación de las familias, donde se fomenta la cultura del ahorro y el apoyo entre sus miembros. "A los niños se les enseña la importancia del trabajo y de aportar a la familia, por lo que desde muy pequeños suelen ayudar en algunas tareas del hogar, y con algo de trabajo informal" (Romero, 2016:58).

Una alternativa de las familias colimenses, descrita en el libro, es el apoyo mutuo que se da entre vecindades, donde los habitantes de la comuna se fortalecen unos con otros para generar un colectivo defensor de su integridad, seguridad y economía para salir adelante; "quienes se dejan conocer y a quienes la familia se acerca para entablar cierto sentido de amistad, empatía y ayuda mutua" (Romero, 2016:59).

En el capítulo 4: "La mujer: única en la unidad doméstica", se describen situaciones que viven muchas mujeres en hogares donde existe pobreza en el cual son jefas de familia. La autora pone mucho énfasis en aspectos tales como la educación sexual, que es fundamental en la decisión de formar una familia, pues aclara sobre la inexistencia de una pedagogía a favor de la enseñanza de la sexualidad tal y como debería ser, por lo cual la educación en este rubro sigue siendo un tabú. Los padres de familia no consiguen establecer diálogo con sus hijos sobre métodos anticonceptivos; además, el desconocimiento provoca relaciones sexuales sin protección que es posible que desemboquen en un embarazo no deseado, común en chicas jóvenes cuya edad oscila entre 15 a 19 años.
Otro de los rubros llamativos tratados es la cuestión de cambio de roles. El padre en épocas pasadas debía ser el proveedor del hogar y la madre se encargaba de las labores

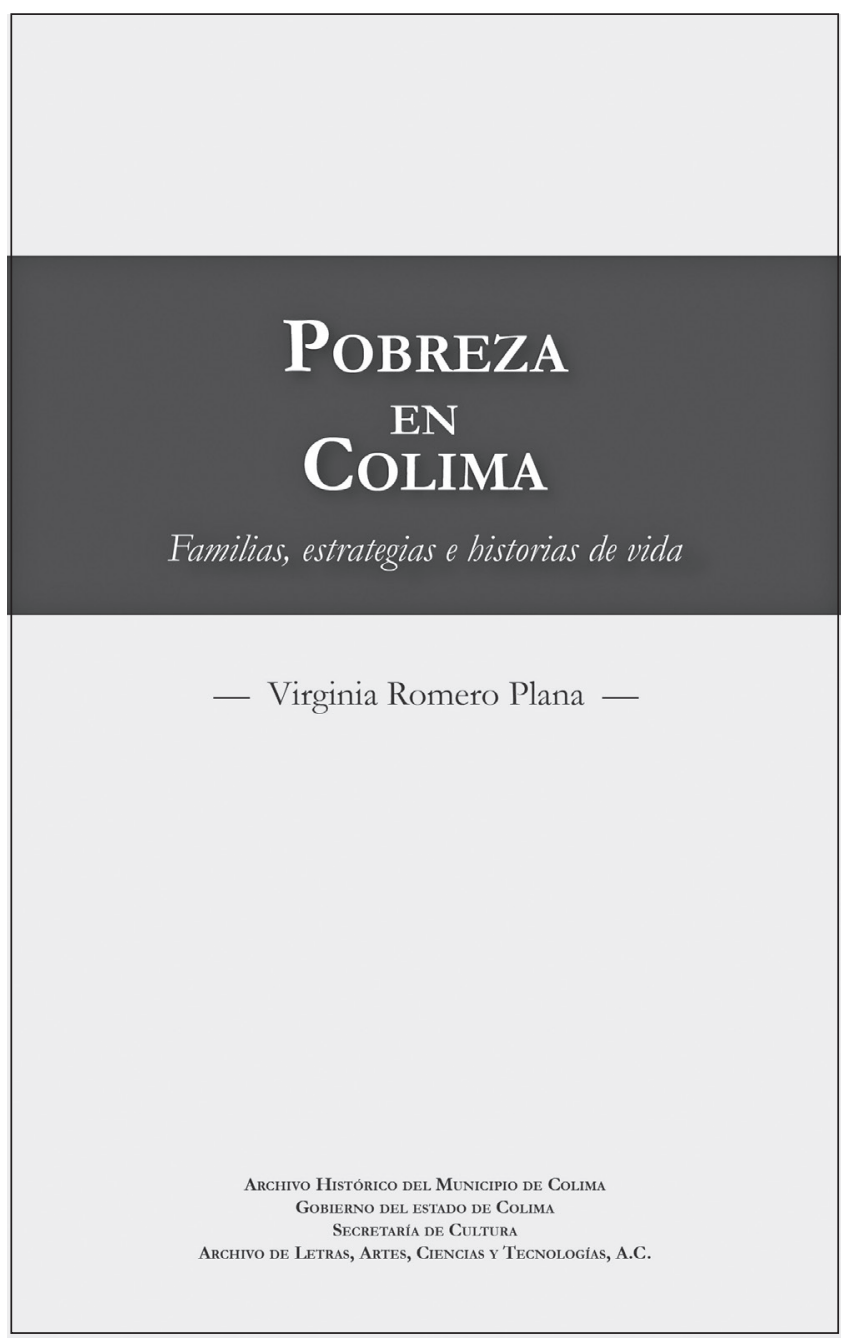

del hogar; pero cuando hay la ausencia masculina, ella se hace responsable de la familia, entonces hará dos trabajos a la par, las labores del hogar y aunado a ello, el empleo externo para solventar las necesidades de la familia. Es triste mirar a los empleadores poco accesibles hacia las madres solteras, hay en resumen "un mercado laboral que no es amable con las mujeres de escasa formación" (Romero, 2016:81).

La doctora Virginia Romero usa el término de feminización de la pobreza. Las mujeres por ser educadas desde pequeñas en labores del hogar, son formadas para entender la profundidad de la unidad familiar; y también, debido a que no tienen estudios no pueden competir por un trabajo; y no tienen estudios porque no se los permiten sus tareas domésticas. Es un círculo perverso en donde las mujeres son doblemente afectadas.

En el capítulo 5: "Convivencia dentro del hogar", se conceptualiza el matrimonio para posteriormente 


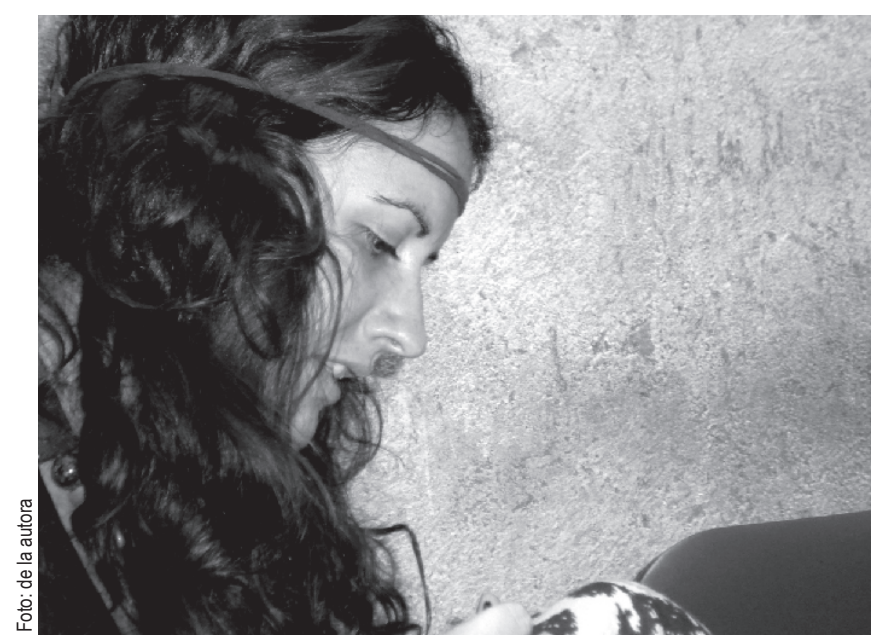

tomarlo como base en la explicación de la dinámica de las interacciones sociales dentro del hogar: "Casamiento con otra persona, bajo una serie de derechos y obligaciones con dicho cónyuge (...) es el paso hacia la conformación de una nueva unidad social" (Romero, 2016:85). Actualmente se encuentra que generaciones jóvenes no se interesan por dicho aspecto, e incluso es tomado con rechazo o indiferencia, pues tanto estar en unión libre como en un matrimonio no garantiza el amor hacia una persona, bien es posible mirar a la pareja como esposo o esposa sin haber firmado un acta.

La pobreza determina preferencias en que es mejor no casarse que hacerlo, por el costo beneficio que implica; además, en caso de separación no hay gastos legales. La unión libre se convierte en una estrategia que sirve para cuidar la estabilidad de quienes no son tan favorecidos económicamente.

En el capítulo 6: "Contexto laboral", se afirma que el empleo en la pobreza es determinante en el modelo capitalista. El desempleo en muchos de los miembros de las familias es una fuerte crisis para conseguir recursos con los que subsistir, y en hogares con núcleos familiares extensos como la de Myrna (mencionada en un principio), se perciben salarios bajos, algunos precarios, e inestables. Las jefas de familia, por ejemplo, para ensamblar perfectamente sus labores dentro y fuera del hogar, se dedican a cocinar, coser, planchar o lavar, y adquieren un sueldo con el que se ayudan para mantener a sus hijos. Los empleos incluso pueden ser enseñanzas de otras generaciones o uso de dones, ejemplo de ello, en la familia Martínez la jefatura femenina se dedica a sobar.

En el capítulo 7: "La educación", se dice que en la sociedad del conocimiento, la inversión más importante es la educación. La pobreza no es sinónimo, de acuerdo con la autora, de bajo nivel educativo; ni el mismo bajo nivel educativo es homólogo a pobreza. Alguien que cuente con contactos para cierto empleo entra e incluso se mantiene en el mercado laboral; y otra persona con demasiados estudios pudiera no encontrar trabajo. Se tiene más probabilidades de mejorar la calidad de vida si con esfuerzo se culmina una carrera. Todas las familias del estudio tienen un nivel educativo circunscrito únicamente a secundaria o primaria, y les es más complicado conseguir un empleo por dicha razón. Muchos optan por el autoempleo para conseguir recursos. Una de las estrategias para erradicar o disminuir la pobreza, sugiere la escritora, es el estudio, como una fuente no solo de progreso, sino de aumento en el capital intelectual, que a futuro elevará la calidad de vida.

\section{Comentarios finales}

El libro "Pobreza en Colima. Familias, estrategias e historias de vida", de la doctora Virginia Romero Plana es un estudio relevante que explica con fino detalle lo que sucede en la pobreza dentro del estado de Colima. Es un libro que puede ser consultado como fuente para otros trabajos académicos; o bien, para lecturas compartidas en una mesa de diálogo. La autora nos asombra desde sus primeros párrafos, y a partir de ahí, se vuelve todo un caminar ameno por las letras hasta llegar al final, como si fuera una historia contada entre un círculo de amistades; así se siente leer el libro.

Recomiendo leerlo a los estudiosos de la cultura social, porque desde mi punto de vista, independiente de que la investigación es sobre una situación en Colima, creo que es común encontrar estas circunstancias en todas las regiones.

Este libro es un texto indispensable para las bibliotecas en facultades como pedagogía, ciencias sociales, o humanidades.

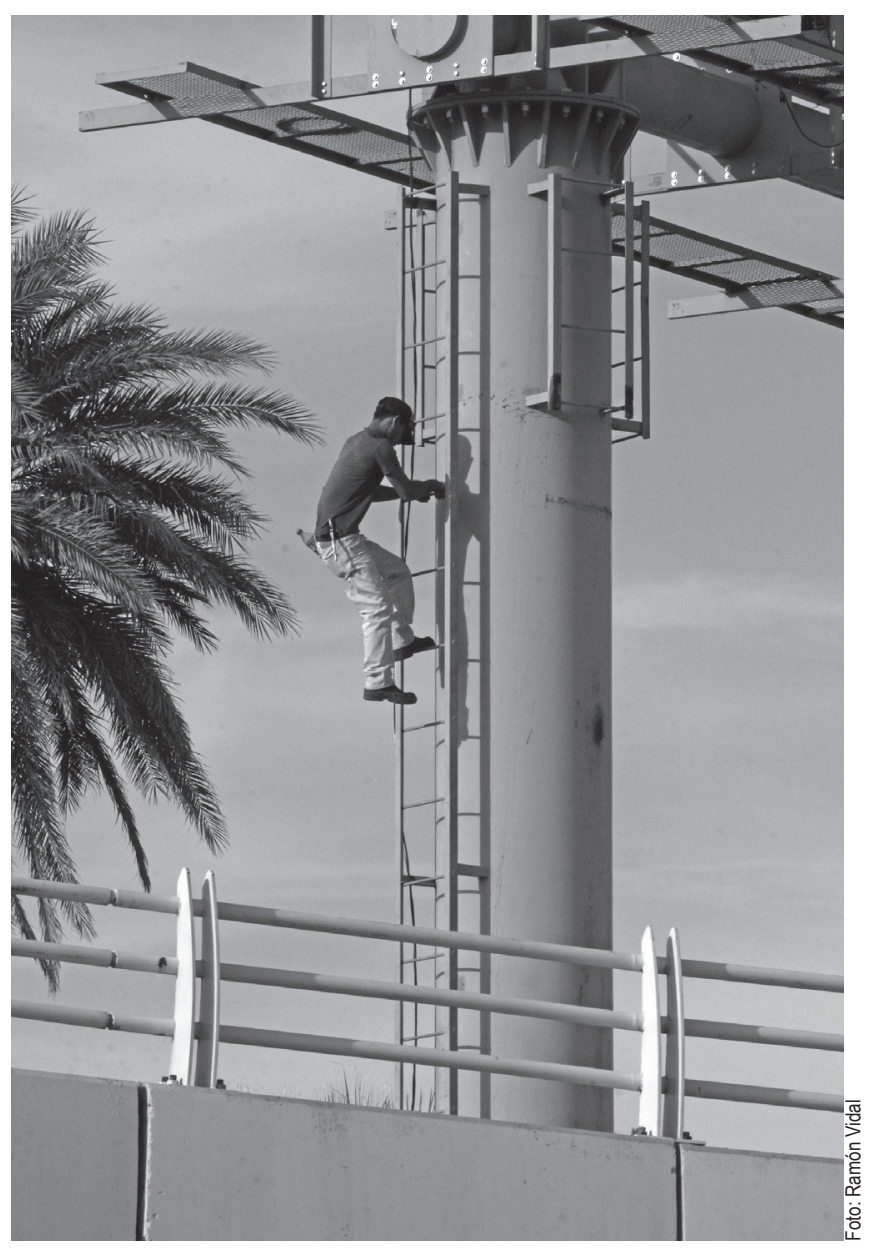

